Book review

Finance or Food? The Role of Cultures, Values and Ethics in Land Use Negotiations, edited by Hilde Bjørkhaug, Philip McMichael and Bruce Muirhead. Toronto: University of Toronto Press. https://doi.org/10.3138/9781487517236

\title{
Land Use Quandaries
}

DOI: http://dx.doi.org/10.5324/eip.v14i1.3543

(cc) BY

This is an open access article distributed under the terms of the Creative Commons Attribution 4.0 International License, which permits unrestricted use, distribution, and reproduction in any medium, provided the original author and source are credited.

This book centres around the phenomenon of land grabbing, which refers to largescale land acquisitions and investments in food soil in developing countries by affluent countries and multinational corporations. Land grabbing moved to the top of the global agenda after the world food price crisis in 2007-8, which generated food riots across thirty countries, the great majority of which was in the Global South (Patel and McMichael 2009). Among several contributing factors was the conversion of land-for-food crops to fuel crops, mandated or subsidized by governments responding to pressures for biofuels. In response, food-exporting countries blocked exports to protect their own consumers, which resulted in a doubling of food prices in just a few months (Bjørkhaug, McMichael and Muirhead 2019).

Arguably, land grabbing - hereafter referred to by the more neutral term "largescale land acquisitions" (see Chapter 6) - may in certain cases have positive effects on local communities, such as increasing productivity. Notably, the World Bank Group supports and promotes large-scale investments in developing countries as a means to economic development, improved agricultural infrastructure and rising employment for the host countries. On the other hand, civil society actors argue that such investments lead to the displacement of local farmers, decrease food security and undermine the livelihoods and basic rights of a large number of people in these countries (Carson 2019). The complexity of the issue is well illustrated by the following passage from Siri G. Carson's contribution:

The issue is complex from the overall perspective of how to promote global food security, and even single investments may appear ambiguous. Even for projects where there are no obvious violations of human rights, it may be argued that while the acquisition of farmland by a large, foreign investor is economically beneficial for the local community, it undermines the long-term food security of that same community (Carson 2019, 120).

The book aims to explicate political, economic and cultural factors underlying large-scale land acquisition. The authors address the practices that support or give rise to such acquisitions and assess the related political and ethical challenges. The chapters rely on extensive empirical material, offer a range of theoretical perspectives - from sociology and cultural studies to situational analysis and philosophy - and provide interesting case studies. The interdisciplinary approach provides the reader with multiple perspectives on questions of land use and the 
political and moral challenges of large-scale land acquisitions and financialization of farmland.

The first three chapters discuss issues related to policy and public discourse. McMichael looks at the politics informing land use, which according to the author is unfortunately influenced by discourses biased in favour of industrial agriculture and large-scale investment and against local farmers and cultural values. He also critically evaluates the role and utility of the UN's Committee on World Food Security (CFS) in addressing land use for the future against the background of his own experience with the deliberations of the CFS. In the next chapter, Campbell and Reynolds discuss how the failure to liberalize international trade in food products opens up ways to rethink and reimagine future politics for food and farming. Rønningen discusses what she sees as paradoxes of agricultural policies and land-use development and control in Europe.

The three following chapters - by Jacob Muirhead, Siri Granum Carson and Jennifer Clapp, respectively - discuss changes in the international governance of agriculture. Carson discusses large-scale land acquisitions in light of the investment practices of the largest sovereign wealth fund in the world: the Norwegian Government Pension Fund - Global (GPFG). According to the ethical guidelines of GPFG, two ethical commitments should guide the management of the fund: (1) fiduciary duties towards the beneficiaries of the fund, including present as well as future generations in Norway and (2) a commitment to avoid investments involving an "unacceptable risk that the fund contributes to severely unethical deeds" (Ministry of Finance 2010, 10). Carson argues that on the basis of these commitments, it is natural to view large-scale land acquisitions as a central ethical concern for the GPFG and Norges Bank Investment Management (NBIM), who manages the fund.

As a matter of fact, however, large-scale land acquisitions and food security are not a central concern of the GPFG. Carson speculates that one reason might be the complexity of the ethical considerations in this area. As noted above, there is no agreement that large-scale land acquisition is in itself a bad thing, and even in concrete cases where one suspects that it is, it can be very hard to evaluate and measure the scale and presence of "unethical deeds". Hence, exclusion from the portfolio - for example, in the form of divestment - which is a measure that GPFG uses in cases where there is a clear violation of ethical commitments, may not be a fitting instrument to deal with the social and environmental problems that follow from large-scale land acquisitions. Instead, Carson suggests that GPFG could use another, and seemingly less dramatic, strategy available in their ethical toolbox that of "active ownership." Active ownership pressures or nudges companies in the right direction with regard to ethical concerns, with the help of constructive dialogue, reporting, etc. However, as Carson acknowledges, this strategy may not be a viable solution in the types of cases under discussion, where ethical considerations are unclear: if GPFG is uncertain whether (sufficiently serious) violations occur, how can the use of pressure, for example, be justified as a means to change the practices of companies?

The next four chapters focus on current farmland challenges, with case studies from Australia, Canada and Norway. Geoffrey Laurence, Sarah Ruth Sippel and Nicolette Larder trace the ways new state-owned and finance-backed entities are investing in Australian farming, and they point out how these new investment 
mechanisms are challenging local and rural cultures and environments. Importantly, questions are being raised about the short- and long-term impacts of changes in the citizenship of owners and the subsequent control, especially of land and water, but also of other natural resources that feed agriculture. Jostein Tapper Brobakk and Bruce Muirhead offer a discussion of how financialization challenges both local and provincial regulation of farmland in the Canadian Prairie region, and how this affects ownership, succession and farming practices of Saskatchewanian farmers. Contrary to what is happening in Australia, Saskatchewan land policy appears to represent an explicit rejection of financialization, even though there is a limited opening for foreign investment in farmland. Furthermore, farms tend to remain mostly family owned, and almost all farm sales are farmer to farmer. A chapter by Hilde Bjørkhaug, Katarina Rønningen and Heidi Vinge, as well as one by Vinge and Siri Øyslebø Sørensen, examine debates over conservation and protection of farmland in Norway, where only a small portion of the land is arable and used for food production. The authors look at how changes in discourse from a focus on narrow agricultural interests to broader environmental concerns have affected policies and created an opening for new alliances between agricultural actors and environmental groups.

In the penultimate chapter of the volume, Allen Alvarez and May Thorseth address ethical challenges to the governance of natural resources, in particular in view of moral obligations that present generations may have toward future generations. The authors examine the nature of such obligations within a framework based on collective environmental rights. That seems reasonable, at least to the extent that - as I understand the authors to suggest - environmental rights are taken to include individual and collective human rights to such things as clean water and ecosystem services. The authors address several challenges to the idea of the right of future generations to be left with adequate resources, including the so-called "non-identity problem" formulated by Derek Parfit (1984). As laid out by Parfit (1984), the non-identity problem says that when choosing between, for example, a policy of depletion and a policy of conservation with regard to longer term resource use, the choice of policy will affect the identities of future people because of the wide-ranging consequences of such policies on procreation - more specifically, on who will procreate at what time and hence on who will be born. The implication is that if present generations choose a policy of depletion, this choice will cause people to exist who would not have existed had the alternative policy been chosen. Moreover, as long as these people have lives worth living - that is, lives that are considered better than not living at all - it seems that they would not be harmed by the policy, because they are not left worse off by it (since the only alternative is non-existence). If we assume, then, that depletion leaves future generations with lives worth living - even if their lives are barely worth living - then it seems that no one will be harmed by it.

To this problem, Alvarez and Thorseth give a type of response which has also been offered by other authors (see Meyer 2016) - namely, to conceive of harm in non-comparable terms. A crucial assumption in Parfit's non-identity argument is that in order to hold that future generations are harmed by a policy of depletion, it must be shown that they are left in a worse-off state than they would have been had the policy not been pursued. And this will not be the case if they have lives worth living - even if those lives are barely worth living and much worse than those of the 
present generation. However, if we say - as do Alvarez and Thorseth - that people are harmed if they are left below some (absolute) threshold of well-being, then the comparison with non-existence is no longer crucial; rather, what is crucial is whether a policy of depletion would leave future generations below the acceptable threshold. If it does, that is problematic - regardless of the identity of the people affected by it, and no matter how their lives compare with the option of not existing.

This seems to me a very promising approach to the non-identity problem. However, a crucial question regarding the approach is where, exactly, to set the threshold. If it is set low - for instance, at the level of basic needs or "functionings" (Alvarez and Thorseth 2019, 259) - the implication seems to be that a policy of depletion may be acceptable after all, as long as it does not threaten basic needs or functionings. But might it not be morally problematic (unjust) for present generations to leave to future generations only what is necessary for basic needs or functioning - at least if present generations themselves enjoy a much higher level of well-being as a result of their consumption? On the other hand, if the bar is set high - for example, "on a par with" that of present generations (Alvarez and Thorseth 2019,259$)$ - this may require too much sacrifice by present generations. Here, a crucial problem will be that of applying an appropriate "discount rate", which is not mentioned at all in the chapter. In sum, in spite of the promise of the approach taken by the authors, defining or determining sufficiency thresholds pose problems that are arguably of central practical and theoretical importance, but which are not adequately addressed in the chapter.

In the final part of their chapter, Alvarez and Thorseth discuss the practical implications of their proposed rights-based framework with regard to land use. Here they appeal to the notion of "overlapping consensus" developed by Rawls, for example in A Theory of Justice (1971), to argue that conflicts of interests and values regarding land use may not be intractable, but rather an unavoidable and manageable feature of modern pluralistic societies. The argument is backed by empirical research - such as that by presented by Vinge and Sørensen in the book - showing that in spite of divergent interests and values, alliances between farmers and environmentalists have formed to promote sustainable land use.

I suggested at the beginning that the book should be applauded for its range of theoretical and empirical perspectives. Nonetheless, the book might be criticised for a certain one-sidedness regarding the political-economic sides of industrialization and financialization. In Chapter 2, McMichael writes, "Industrial agriculture [...] does [not] have an evident social purpose - it is driven by distant market signals and private wealth and not the cultural needs of local citizens" (McMichael 2019,29). Statements such as this would be contested by those who see the globalized "free market" as serving the important social purpose of global economic growth and reduction of poverty - even as it responds to "distant market signals", and even if local communities may not receive the immediate benefits. Related to this, the book might have benefitted from a chapter providing a more principled and detailed discussion of the advantages and disadvantages of largescale land acquisitions and financialization of agriculture, for example from the perspective of welfare economics or political theory. On the other hand, chapters such as the one by Carson showcase the complexity of the issue, and the politicaleconomic question raised above might be one for further research. 
The main contribution of this book is to highlight the tension between regarding land as a financial asset on the one hand, and on the other seeing land as culture and livelihood. As the editors state in the closing chapter of the book:

To view land as a financial asset, as it is now seen in the age of market uncertainty, loses sight of the fact that much of the land being commandeered today is a common property resource and/or represents a livelihood for millions of small producers, farmers, pastoralists, fisherfolk, and forest-dwellers (McMichael, Bjørkhaug, and Muirhead 2019, 270).

The volume does a good job of raising awareness of and analysing this tension. It offers fruitful ways of theorizing and thinking about dilemmas of large-scale land acquisitions and financialization, and suggests some ways to deal with them. In sum, the book is an important interdisciplinary contribution to agricultural studies and deserves to be read and debated by everyone working on cultural, political and moral questions of land use.

Espen D. Stabell

NTNU Norwegian University of Science and Technology espen.d.stabell@ntnu.no

\section{References}

Alvarez, Allen, and May Thorseth. 2019. "Intergenerational Justice and Obligations to Future Generations: Towards Environmental Rights in Land-Use Policy." In Finance or Food? The Role of Cultures, Values, and Ethics in Land Use Negotiations, edited by Hilde Bjørkhaug, Philip McMichael and Bruce Muirhead, 243-269. Toronto: University of Toronto Press. https://doi.org/ $10.3138 / 9781487517236-013$

Bjørkhaug, Hilde, Philip McMichael, and Bruce Muirhead. 2019. "Introduction to cultures, values, ethics, and arguments on agricultural land." In Finance or Food? The Role of Cultures, Values, and Ethics in Land Use Negotiations, edited by Hilde Bjørkhaug, Philip McMichael and Bruce Muirhead, 3-18. Toronto: University of Toronto Press. https://doi.org/10.3138/9781487 517236-002

Carson, Siri. 2019. "Dirty Hands, Clean Conscience? Large-Scale Land Acquisitions and the Ethical Investment Strategy of the Government Pension Fund Global." In Finance or Food? The Role of Cultures, Values, and Ethics in Land Use Negotiations, edited by Hilde Bjørkhaug, Philip McMichael and Bruce Muirhead, 108-123. Toronto: University of Toronto Press. https://doi.org/ $10.3138 / 9781487517236-007$

McMichael, Philip. 2019. "The Twenty-First-Century Land Question and Its Politics." In Finance or Food? The Role of Cultures, Values, and Ethics in Land Use Negotiations, edited by Hilde Bjørkhaug, Philip McMichael and Bruce Muirhead, 19-42. Toronto: Toronto University Press. https://doi.org/10.3138/9781487517236-003

McMichael, Philip, Hilde Bjørkhaug, and Bruce Muirhead. 2019. "Land and the Value Calculus: Towards a Reculturalization of Farmland." In Finance or Food? The Role of Cultures, Values, and Ethics in Land Use Negotiations, 
edited by Hilde Bjørkhaug, Philip McMichael and Bruce Muirhead, 270285. Toronto: University of Toronto Press. https://doi.org/10.3138/ 9781487517236-013

Meyer, Lukas H. 2016. "Intergenerational justice." Stanford Encyclpedia of Philosophy (Summer 2016 Edition), Edward N. Zalta (ed.), URL = $<$ https://plato.stanford.edu/archives/sum2016/entries/justiceintergenerational/ $>$.

Ministry of Finance. 2010. "Consultation Paper: Evaluation of the Ethical Guidelines for the Government Pension Fund - Global ".

Parfit, Derek. 1984. Reasons and Persons. Oxford: Oxford University Press.

Patel, Raj, and Philip McMichael. 2009. "A political economy of the food riot." Review (Fernand Braudel Center):9-35.

Rawls, John. 1971. A Theory of Justice. Cambridge, Massachusets: Harvard University Press. 